\title{
Water in Sport: overall results from 8 local government areas
}

\section{Introduction}

During 2018-2020, VicHealth supported 8 local governments to improve access to water and create healthy drink environments in their local sport and recreation facilities.

The 8 funded councils that partnered with VicHealth to reduce sugary drink consumption were:

$\rightarrow$ East Gippsland

$\rightarrow$ Frankston

$\rightarrow$ Greater Geelong

$\rightarrow$ Greater Bendigo

$\rightarrow$ Greater Shepparton

$\rightarrow$ Melton

$\rightarrow$ Northern Grampians

$\rightarrow$ Yarra Ranges

\section{Objectives}

$\rightarrow$ Increase the promotion and supply of water and reduce the availability and supply of sugary drinks in community sports and recreation facilities.

(>50\% GREEN drinks like water and <20\% RED sugary drinks)

$\rightarrow$ Strengthen council policies and practices to enable longerterm changes to healthy drinks environments across council-owned sport and recreation facilities.
The Healthy Choices: food and drink classification guide uses a traffic light system to classify foods and drinks as:

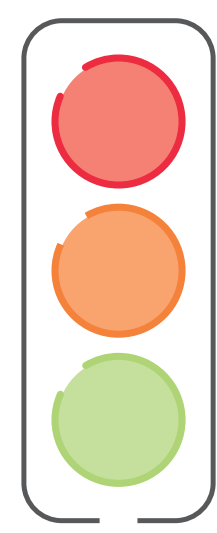

RED: Limit intake

AMBER: Choose carefully

GREEN: Best choice
Why

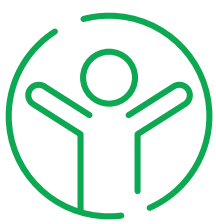

Local Governments have a

commitment to supporting the health and wellbeing of their community.
The environments in which we live, work, learn, and play are key drivers of the types of food and drink we consume. Local government can play a key role in implementing policies and practices to improve local food and drink environments.
There is community support and expectation for healthy food and drinks $-75 \%$ of customers surveyed from all Water in Sport councils believed that sport and recreation facilities should promote healthy eating. 


\section{Outcomes}

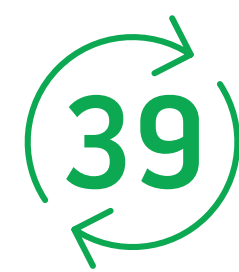

39 facilities made changes to create healthy drinks environments.

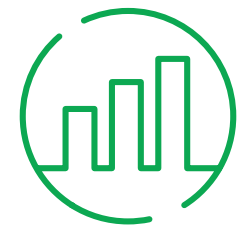

Overall, availability of 'GREEN' drinks increased from $43 \%$ to $63 \%$ of all drinks and 'RED' drinks decreased from $39 \%$ to $11 \%$ of all drinks.

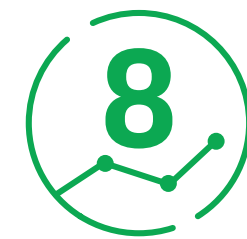

In 8 seasonal facilities (such as outdoor pools), 'GREEN' drinks increased from $41 \%$ to $51 \%$ and 'RED' drinks decreased from $48 \%$ to $25 \%$ of drinks sold each week between April 2018 to February 2020.

In 9 out of 10 non-seasonal facilities (such as sports and recreation centres) there was no change in drinks revenue.
Every council has taken steps to implement healthy food retail facility policies to sustain the changes. As of February 2020, four councils had implemented healthy food retail policies.

\section{Recommendations for creating healthy food retail environments in your community}

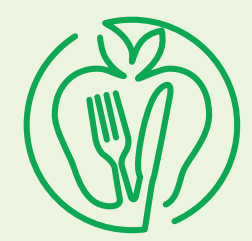

Use the VicHealth toolkit for creating healthy food and drink environments in community food retail outlets.

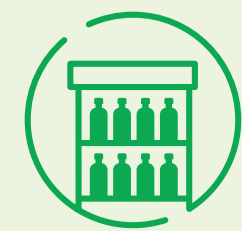

Start by trialing a small 'quick win' which is easy to implement and unlikely to cause revenue loss, such as rearranging the fridge to put 'GREEN' drinks at eye-level.

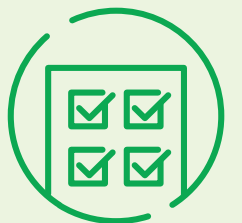

Develop healthy food environment policies and procedures for councils and facilities.

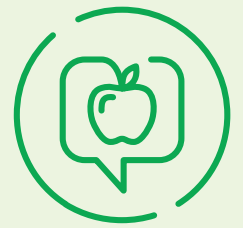

Contact the Healthy Eating Advisory Service for practical implementation support.

\section{Healthy
Eating
Advisory
Service Nutrition}

